This item was submitted to Loughborough's Research Repository by the author.

Items in Figshare are protected by copyright, with all rights reserved, unless otherwise indicated.

\title{
Energy consumption of water-filled glass (WFG) hybrid building envelope
}

PLEASE CITE THE PUBLISHED VERSION

https://doi.org/10.1016/j.enbuild.2020.110050

PUBLISHER

Elsevier

VERSION

AM (Accepted Manuscript)

PUBLISHER STATEMENT

This paper was accepted for publication in the journal Energy and Buildings and the definitive published version is available at https://doi.org/10.1016/j.enbuild.2020.110050.

\section{LICENCE}

CC BY-NC-ND 4.0

\section{REPOSITORY RECORD}

Gutai, Matyas, and Abolfazl Ganji Kheybari. 2020. "Energy Consumption of Water-filled Glass (WFG) Hybrid Building Envelope”. Loughborough University. https://hdl.handle.net/2134/12251471.v1. 


\title{
Energy consumption of water-filled glass (WFG) hybrid building envelope
}

\author{
Matyas Gutai; Abolfazl Ganji Kheybari \\ a School of Architecture, Building and Civil Engineering, Loughborough University, Epinal Way, LE11 \\ 3TU Loughborough, United Kingdom \\ ${ }^{\circ}$ Faculty of Civil Engineering, TU Kaiserslautern, Kaiserslautern, Germany \\ * corresponding author. Email address: M.Gutai@lboro.ac.uk (M. Gutai)
}

\begin{abstract}
The thermal properties of building envelopes have a major effect on energy consumption and indoor comfort, which is even more significant for glass buildings. The current solutions for mitigating this is either improving U-value and SHGC with additional layers, utilizing shading or changing the transparency of the glass with adjustable coating. These solutions address the problem of energy consumption to a certain extent but cannot effectively manage and take advantage of the excessive solar radiation. Moreover, shading solutions obstruct the view to the outside and have negative impact on daylighting.

This paper introduces Water-filled glass (WFG) technology, a transparent glazing system that utilizes water infill to improve thermal properties of the building envelope. The impact of WFG on cooling and heating energy demand is evaluated by studying different glazing configurations for WFG in different climates.

The significance of this evaluation is that a comprehensive climate-based assessment considering absorption and insulation-based options for WFG is presented here for the first time: the paper evaluates different options of glazing system and mechanical systems in all major Köppen-Geiger climates (13 cities). Additionally, as a novel approach, the simulation results presented here identify climates where improving SHGC is more ideal for thermal performance than improving U-value even if it occurs by compromising the latter and distinguishes absorption-based and insulation-based scenarios respectively.

The results show that absorption-based energy model is a viable option, which results in energy savings between $3-84 \%$ in value of US $\$ 0.99-24.25 / \mathrm{m} 2$ a depending on climate. The discussion includes simulation and comparison with identical spaces using standard technology that follows the local building code and conventions. The climate-based evaluation of water-filled glass can improve energy consumption of buildings and offer a sustainable strategy for glass envelopes by absorbing and reusing heat where transparency becomes an asset instead of being a liability.
\end{abstract}

\section{Keywords}

Building sustainability, Water-filled glass, glazing, Solar control, energy-efficiency, glass buildings 


\section{Introduction}

Controlling and managing solar energy gains is a major component of energy consumption of HVAC systems in buildings. The impact of glass facades and windows on energy demand is considerable because of transmitting solar gain and their low insulation capacity, which makes energy management of the building envelope a critical aspect for glass buildings.

Considering solutions for mitigating energy demand and insolation for glass surfaces, the options explored in previous research works can be divided into four groups. The first group increases reflectance of the glass to protect indoors from excess solar heat, like electrochromic (EC) [1] smart windows (SPD) [2] or switchable windows (PDLC) [3]. The second option is to improve thermal resistance of the building envelope, i.e. by improving its performance with increased number of layers [4]. The third approach is to use internal or external shading. Finally, a fourth approach is to control the transmitted heat by absorbing it with a fluid medium, like ventilated air stream in the glazing that either cools the window by circulating outside air between the glass panes [5] or preheats the air before entering indoors [6]. Another option is utilizing "circulating water chamber", which has the benefit of capturing solar energy and turning that potential energy load into a renewable energy source [7]. The significance of this technology is that compared to other advanced glazing (i.e. PCM, EC, SPD or PDLC), WFG saves energy without changing the optical transparency of the window. Additional advantage is that WFG is beneficial for thermal comfort too because the water can be heated or cooled to a desired temperature. This transforms glass façade from a liability to an asset because WFG improves thermal comfort while other glazing solutions compromise it to a certain extent.

Since water-filled glass system has been introduced first in 2007 [8], in 2009 [9] and was patented [10] by the author, the technology is under continuous research. P.G. Loutzenheiser et al. [11] offers empirical validation on thermal behaviour of glass in this aspect. This model considered heat exchange mainly between indoors and the external environment. A two-dimensional model for ventilated multilayered window is presented by K.A.R. Ismail. J.R. Henriquez [12] extended this model by adding a heat flux that is parallel to the window surface as the result of ventilation. The energy model they used is similar to that of water-filled glass with constant water flow: Hernandez and Sierra built on energy models of ventilated windows to determine Solar Heat Gain Coefficient (SHGC) of water flow glazings [13] The impact of solar gain on energy consumption also depends on climate: Gasparella et al. [14] and Bui et. al. [15] presents that the effect of insolation is more important for hot climates, where high thermal resistance is less favourable over SHGC than in cold climate. This is an important detail for water filled glass windows because the fluid flow has a stronger influence on solar transmittance than on heat transmission. P. Sierra and J.A. Hernández [13] presents that water flow glazing can change SHGC and $U$ values dynamically as both depend on the water flow within the chamber. In addition to absorption of water layer, this can lead to further energy savings as the envelope can adapt to external conditions like ambient temperature and solar gain. T.-T. Chow et al. [16] compares water flow in clear and absorptive glazing to present the benefits in buildings with stable hot-water demands. The absorbed solar energy was reused by the hot water supply system of the building, which increased the energy savings further. T. Gil-Lopez and C. Gimenez-Molina [17] evaluated the impact of water-flow glazing on annual energy consumption in continental climate. The results have shown that the water filled glass can save energy in both heating and cooling period by capturing and utilizing solar heat. C. Li et al. [18] presented the annual performance of water filled window in humid tropical climate. T.-T. Chow et al. [19] introduced a mathematical model to analyse the thermal characteristics of water flow reflective glazing in humid tropical climate. He concluded that the application is highly suitable for both summer and winter conditions with generally better performance during winter than summer as the water layer improved solar gain with a negative effect on heat transmission. The water filled window showed potential as a cooling device as the angle of incidence had major effect on the performance when the solar radiation was high. Y.L. Lyu and T.-T. Chow evaluated the impact of header designs [20] and design configurations [21] on the water flow using CFD and presented a numerical analysis on the potential of using PCM in the fluid volume [22]. Finally, L.Y. Liu et. al. [23] presented an energy analysis and simulation of water filled glass window for different climate conditions in China. Additionally, the author of this article built experimental buildings with connected water-filled building envelope for different climates (Water House 1.0 in Hungary [24], Water House 2.0 in Taiwan [25]) and published a book about the structural and thermal characteristics of water-filled building envelopes [26].

The previous research projects explore the thermal properties of water filled glass windows in general and analyse its impact on energy consumption. However, these evaluations and tests were limited to one configuration (double glass with water infill). Extending these evaluations with additional options for structural layout and mechanical systems that consider climate scenarios is further beneficial because of five main reasons. First, the utilized models do not explore options for mechanical systems that could improve the performance further, like presenting options for reusing the captured heat or 
using earth coupling. Second, the research projects conducted do not assess options for glass layouts in different climate, which would offer another chance for improvement since a triple glass option (shown in Figure 1) would perform better in certain climates while double glass would be more ideal in others. Third, the simulations conducted previously on WFG are limited to windows (and not on a whole building) and the programs utilized are not open source or widely available, while there is a great potential in introducing open source simulations for this system like Window or TRANSYS. Fourth, previous research did not develop WFG into a construction system that can be integrated into a building and therefor simulations were not informed by the technical, mechanical and design decisions of a WFG system. Finally, the current simulations offer no comparison to standard double glass window options, which would be ideal because some aspects of the energy gain utilized in the energy models (i.e. solar gain during heating period) is not specific to water filled glass windows. This last element is quite significant because water filled glass offers us the option to tailor U-value and SHGC to each climate. Unlike standard glass windows, water filled glass reutilizes the absorbed energy and becomes a direct asset in the final balance, which divides the analysed scenarios into absorption- and insulation-based climates. This means that instead of focusing either on insulation (which would be the conventional approach for standard glass) or on absorption (previous water-glass research), the most effective approach should incorporate both before climate specific layouts can be defined. WFG gives the designer the opportunity of choosing between prioritising either insulation or absorption, which is not the case for standard glass. The aim of this paper is to define and present new climate groups that can inform such prioritisation and additional steps in the decision-making process.

In order to understand better the significance and effect of water-filled glass system, it is necessary to evaluate and consider its insulation and absorption aspects for each climate specifically. This paper introduces the design aspects and challenges of this approach by analysing each aspect and evaluating options for each climate. This does not mean that WFG layout for an 'absorption-based' climate will not be able to heat indoors or would not have any insulation. Firstly, this would not be possible for most cities since maintaining both cooling and heating for glass buildings is necessary to a certain extent, which is also shown in the simulation results. Secondly, designing WFG facades for one mode of operation would limit the technology in an ineffective way because one of the important aspects of WFG is that it is capable for both heating and cooling, which is something that current commercially available glazing cannot do. The goal here is therefore to inform prioritisation, which can support further design decisions (i.e. number of glass layers, types of glass or coatings).

\section{Methodology}

The methodology of the research is divided into two main parts: design aspects and simulation study. The first part (2.1.) focuses on the relationship between WFG system configuration, mechanical system options regarding the local climate. Each aspect has multiple configurations, which had to be analysed and evaluated before one option could be determined for simulation. The second part (2.2.) presents the dynamic simulation of the selected glass configuration and mechanical system.

\subsection{Water-glass envelope: design aspects and climate considerations}

The section is divided into four parts. The first introduces the four climate groups based on WFG performance: depending on heating-cooling demand and insolation of the site, the system can lower operational energy either relying on absorption only or also reusing the captured heat. The second part introduces options for mechanical systems. This is necessary as the proposed system guides the simulation, in particular considering the temperature of the ground for underground heat rejection for free cooling. The third part evaluates options for glass configurations and offers justification for using triple plane option for all climates. Finally, the fourth part introduces the climates of the selected 13 cities in reference to Köppen-Geiger climate classification, which were selected based on the updated climate map of Biometeorology group [27]. Each location is from a different climate, which was important to evaluate the energy performance of WFG in various combinations of heating/cooling demand and solar gain. 


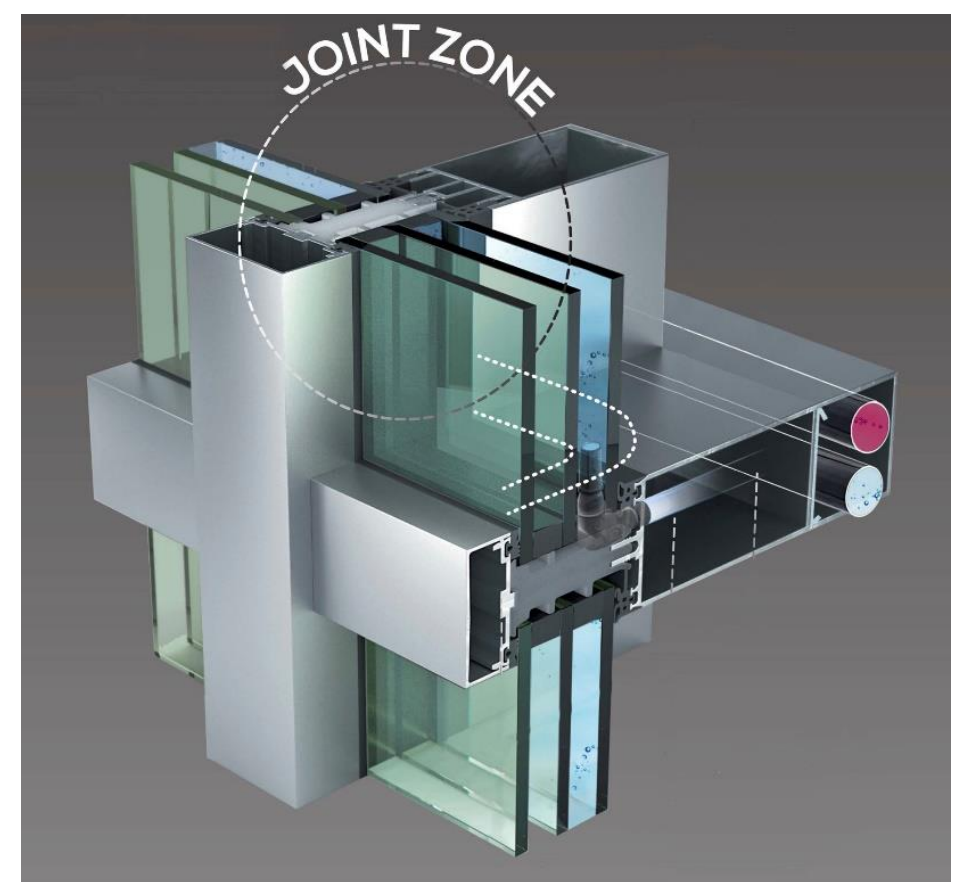

Figure 1: Typical configuration of Water-filled glass façade

2.1.1. Water as "coating": direct-indirect energy savings and climate groups

Water is an ideal structural infill for glass facades because of its unique physical properties, including large heat storage capacity and transparency. Water is also an ideal medium for energy dissemination between parts of the building envelope and/or building parts. Among all these aspects the most significant is the absorption coefficient: water absorbs a large proportion of heat in the IR and UV spectrum while leaves the visible part relatively intact [28]. This aspect of water is crucial when it comes to energy savings of WFG: the energy models presented by previous research determine the energy savings based on the captured heat within the water layer, since this lowers demand on cooling. These savings can be considered as direct primary savings in energy demand of the building, where 'primary' indicates that the final energy savings also depend on the type of mechanical system. Naturally, direct savings are the most efficient in warmer climates, where indoor solar gain and radiation is not beneficial and plays a more significant role in the overall energy consumption of the building.

Mitigating heat gain by absorption is not the only impact that water-filled glass has on energy demand. Additional energy savings can be achieved by reusing the captured energy for heating, which can be considered as indirect energy savings. This aspect becomes crucial in climates with lower cooling and higher heating demand, which would require better insulation (U-value) over absorption (SHGC). Compared to standard glass windows, water layers in WFG systems improve the latter and weaken the former, which is why consideration of climate becomes essential.

In addition to lowering operational energy, the significance and purpose of combining direct and indirect energy savings for WFG is therefore to increase the applicability of the system as these two combined savings can offer viable solution for more climate options. In respect of energy conservation strategies of water-glass, climates can be divided into four groups.

The first group is cooling dominated hot climates, where heating demand is minimal and solar and/or radiation gain is high. In these areas the absorption of the water-glass alone is sufficient to achieve energy savings. From the perspective of this study and WFG technology, these areas are considered as absorption-based climates.

The second group consists of areas where external heat gain is still significant (either during the summer or for the whole year) but there is also a relevant heating demand. Compared to energy demand for a standard glass scenario, the cooling demand is lower and heating is higher because the better absorption and the weaker U-value of WFG. The overall energy savings are therefore less than for the previous option, but the savings in absorption are still higher than the energy loss on heating, which means that improving absorption in these climates is still more beneficial that insulation. For water-filled glass envelopes, these areas can be defined as intermediate climates.

The third group includes the areas with relevant heating period combined with solar gain and with low cooling demand. In case of these climates the absorption alone is not sufficient to achieve energyefficiency because (compared to a standard glass scenario) the losses in heating demand exceed the 
gains in absorption (because of higher U-value). These areas can only benefit from WFG if the system utilises both direct and indirect gains. Considering WFG envelopes, these climates can be defined as hybrid climates.

Finally, the remaining areas include climates with heating-dominated areas and minimal heat gain the whole year. These climates are not ideal for utilisation of WFG, except for specific circumstances i.e. when optical clarity is important. In these areas changes in $U$-value have much more significant impact on energy consumption than absorption. In terms of WFG, these climates can be defined as insulationbased climates.

It should be noted that absorption-based and intermediate climate groups do not consider indirect energy savings in their definition. Naturally, this distinction does not suggest that it cannot be utilized nor that it would not be beneficial. The description merely suggests that they are not a requirement for energy-efficiency in these areas, which is the case for the other climate groups. Additionally, it should be pointed out that the simulations and mechanical system does not consider using absorbed heat for other ways than heating (i.e. hot water supply) and that absorbed heat gain is only considered in the simulation when there is heating demand for the same period (short-term storage). The reason for that is because the collected energy would be much higher than the possible demand and also because the demand would be specific to function and climate. However, in case of specific scenarios (swimming pool), these options would be also viable.

Consideration of climate groups is necessary to tailor the structural and mechanical aspects of waterglass to the specific site condition because each combination of glass layout and mechanical system is more ideal for either direct or indirect energy savings. These options are briefly reviewed in the chapter below.

2.1.2. Managing thermal energy: Options for mechanical systems in combination to WFG

Depending on climate conditions, there are various possibilities to manage the collected energy gain.

- Water supply with constant temperature (i.e. using water infrastructure) for cooling and preheating: This option was used on water-glass prototypes previously and has been effective for a variety of climates with heating and/or cooling demand. The constant water temperature for these cases was the temperature of the water supply network, which was about 15-17 Celsius. This level was sufficient for both cooling and preheating. The solution is effective in saving energy, however, its limitation is that it requires a constant water supply and it does not take advantage of the absorbed heat.

- Heat storage option (for short-term use): This option stores the captured heat for later use, ideally within 24-48 hours. The energy can be used for various purposes, including DHW, water pools or heating. This solution is ideal for buildings with significant hot-water consumption and for climates with heating periods combined with relevant solar gain.

- Heat storage option (for long-term use): This option is similar to the one mentioned previously with the difference that some of the heat is stored for longer periods. This can be a seasonal storage, which absorbs summer gain and reuses it in autumn for heating. This option works well with hybrid climates that have less solar gain during heating periods. Depending on the amount of captured heat, this solution can work also for insulation-based climates.

- Heat storage option (with heat radiation): This option absorbs the heat during cooling periods and utilizes designated building part(s) to radiate the energy back to the environment later when possible. (A good example for this method is absorbing heat during the day and radiating it back during night, especially when the building is unoccupied). This solution is ideal for buildings with low domestic hot water demand and/or with high solar and radiation heat gain. Absorption-based climates are typical cases for such option because the daily heat gain is likely higher than the heat energy demand (which is mostly limited to hot water use).

- External heat mass: This option connects the mechanical system with a larger thermal mass. This could be typically earth coupling or a large water volume (for example sea, river or lake). This solution can be used to release the absorbed heat to the environment with small energy investment. Similar to the first option, the water supply temperature can be considered relatively constant. Depending on the temperature level of the system, water can be used for either heating/cooling or both. The advantage of this solution is its energy-efficiency, which makes water-glass effective for most climates (including insulation-based climate group) even if the Window-to-Wall-Ratio (WWR) of the building is higher than the average in the area. (For colder climates, this would be typically over $25-30 \%$ ).

- Combination with heat pump (cooling and heating): This option can be considered as the most universal solution as it only requires a heat-pump. Depending on the type of heat sink (air, 
ground, water source, etc.), this option can be a viable solution for water-filled glass. Its disadvantage is that it cannot take advantage of the absorbed energy by itself therefore it should be ideally combined with one of the options mentioned above.

The options mentioned here can be combined depending on the available resources and the climatic conditions of the site.

2.1.3. Water-filled glass design: design considerations of double, triple and quadruple glass layout climate considerations and differentiation between climate groups have an impact not only on mechanical system but also on the glass layout of water-glass. Increasing the number of glass layers improves the insulation of the envelope (U-value) but would have a negative impact on the absorption of the water layer, especially if the layers are combined with additional coatings. Low-E coating for example, has a positive impact on the performance of glass during heating periods, but also lowers the amount of water absorption. Practically, the number of glass layers have a direct impact on economic viability in sense of construction cost and also in terms of energy performance: a WFG facade for an insulation-based climate would require improvements in U-value over absorption in the water layer, but this is not necessarily the case for other climate groups.

The previous research projects introduced two types of possible glazing for water-glass envelope.

The simplest solution for WFG layout is to utilize a double glass for the envelope with water infill in between. This option has the highest U-value and the most possible water absorption. This layout was predominantly used in previous projects for hot climates, like case studies in Hong Kong [19] and the Water House 2.0 experimental building in Taiwan [25]. As the properties of the glass would suggest, this option is more ideal for absorption-based and intermediate climate groups and would not work in colder climates.

The second option is to use a triple glass layout with water either in the outer or inner gap. These options were analysed by previous research, which concluded that the latter option is more ideal from an energy perspective. This solution is ideal also considering climate and operation: the risk of the water freezing is much lower and the heat-exchange between indoors and the water layer is more effective, which enhances the cooling/heating impact of water-filled glass. This option was tested in Water House 1.0 building in Hungary, where the climate justified the additional insulation layer. The external air gap of the triple layered WFG improves U-value, which is more ideal for hybrid and insulation-based climate groups, even if the absorption becomes slightly lower. This effect can be further increased with additional coating, which lowers heat loss during winter but has the same effect on absorption of the water layer. As the simulation shows, generally, the higher the heating demand, the more important is U-value over SHGC.

It should be mentioned that although double-glass layer is more effective for hot climates, in reality this is not necessarily the case. This is mainly because high transmission is not ideal in case there is a heating period. Additionally, the lack of insulation could impact the performance of the system in case of cooling: if the external temperature is higher than indoors, the water layer absorbs more energy from outside instead of cooling indoors. An external air gap and insulation would effectively balance that. Finally, a double layered water-glass could be also problematic in case the humidity is very high because it could cause condensation on the external layer of glass even if the water temperature is above internal dew temperature. This also can be effectively avoided with additional glass layers, which points to the triple layered WFG option for hot climates too. However, it should be noted that even if the optimal layout and number of glass layers can be the same for all climate groups, the type of glass and potential coatings should be different: if the absorption of the water layer is preferred, external clear glass would enhance absorption better, while in the case of heating dominated climates, coatings would be more effective.

To simplify the possible options and to offer a comparison, the water-glass preferences here are presented with clear glass in all climate scenarios and with triple glazing, as shown in Figure 1. The main justification for this was that the base references for comparison were standard glazing that have no coatings either. However, it should be noted that water-glass would perform better in heating dominated climates with additional coating.

\subsubsection{Climate considerations}

The climate considerations of the simulation followed the Köppen-Geiger classification and covered all major climate types in the world. Since the energy performance of water-glass is affected by heating demand and solar gain, these aspects were taken into account when selecting the 13 cities for the simulation. The climate classification of each city was based on latest publications or the Kottek revisions. The following weather data sets were considered by using epw file format of Ladybug EPW Map Tool in simulation: 
- Hot climates (Köppen-Geiger category A and B)

- Hot summers and winters or category A (Tropical rainforest - Singapore [29] and Tropical savanna - Brasilia [30])

- Hot summers and cold winters or category B (Tehran [31] and Torrance California [27])

- Temperate/mesothermal climates (Köppen-Geiger category C)

○ Humid Subtropical (Tokyo [27], Shanghai [32], New York [27], São Paulo [27], Srinagar [27], Mannheim [27])

- Continental climates (Köppen-Geiger category D)

$\bigcirc \quad$ Warm summer continental (Debrecen [27])

- Humid continental (Beijing [27])

- Polar climates (Köppen-Geiger E)

○ Tundra climate (Falklands, Mount Pleasant [27])

Table 1: Comparison and climate classification of selected cities

\begin{tabular}{|c|c|c|c|c|c|c|}
\hline City & Country & Latitude & Longitude & $\begin{array}{c}\text { Altitude } \\
(\mathbf{m})\end{array}$ & $\begin{array}{c}\text { Avg. ground } \\
\text { temperature } \\
(\mathbf{C})\end{array}$ & Climate \\
\hline Singapore & Singapore & 1.37 & 103.98 & 16 & 27.5 & $\mathrm{Af}$ \\
\hline Brasilia & Brazil & -15.87 & -47.93 & 1061 & 21.6 & $\mathrm{Aw}$ \\
\hline Tehran & Iran & 35.41 & 51.19 & 1190 & 17.0 & Bsk \\
\hline Torrance, California & United States & 33.783 & -118.317 & 27 & 16.3 & Bsk \\
\hline Tokyo & Japan & 36.18 & 140.42 & 35 & 12.8 & Cfa \\
\hline Shanghai & China & 31.17 & 121.43 & 7 & 16.0 & Cfa \\
\hline New York & United States & 40.78 & -73.97 & 40 & 12.2 & Cfa \\
\hline São Paulo & Brazil & -23.62 & -46.65 & 803 & 19.9 & Cfa \\
\hline Srinagar & India & 34.08 & 74.83 & 1587 & 13.5 & Cfa \\
\hline Mannheim & Germany & 49.52 & 8.55 & 100 & 10.9 & Cfb \\
\hline Debrecen & Hungary & 47.48 & 21.63 & 112 & 10.0 & Dfb \\
\hline Beijing & China & 39.8 & 116.47 & 32 & 12.5 & Dwa \\
\hline Falklands, Mt. & $\begin{array}{c}\text { British } \\
\text { Pleasant }\end{array}$ & -51.823 & -58.447 & 74.4 & 6.5 & ET \\
& Terseas & & & & & \\
\hline
\end{tabular}

The categorisation would help better understanding of preferable glass layout and mechanical system for each location and would highlight the difference between absorption or insulation preferences for each. This is necessary because in case of WFG, these two factors work against each other, therefore it is necessary to define design preferences before the final glass layout can be determined. 


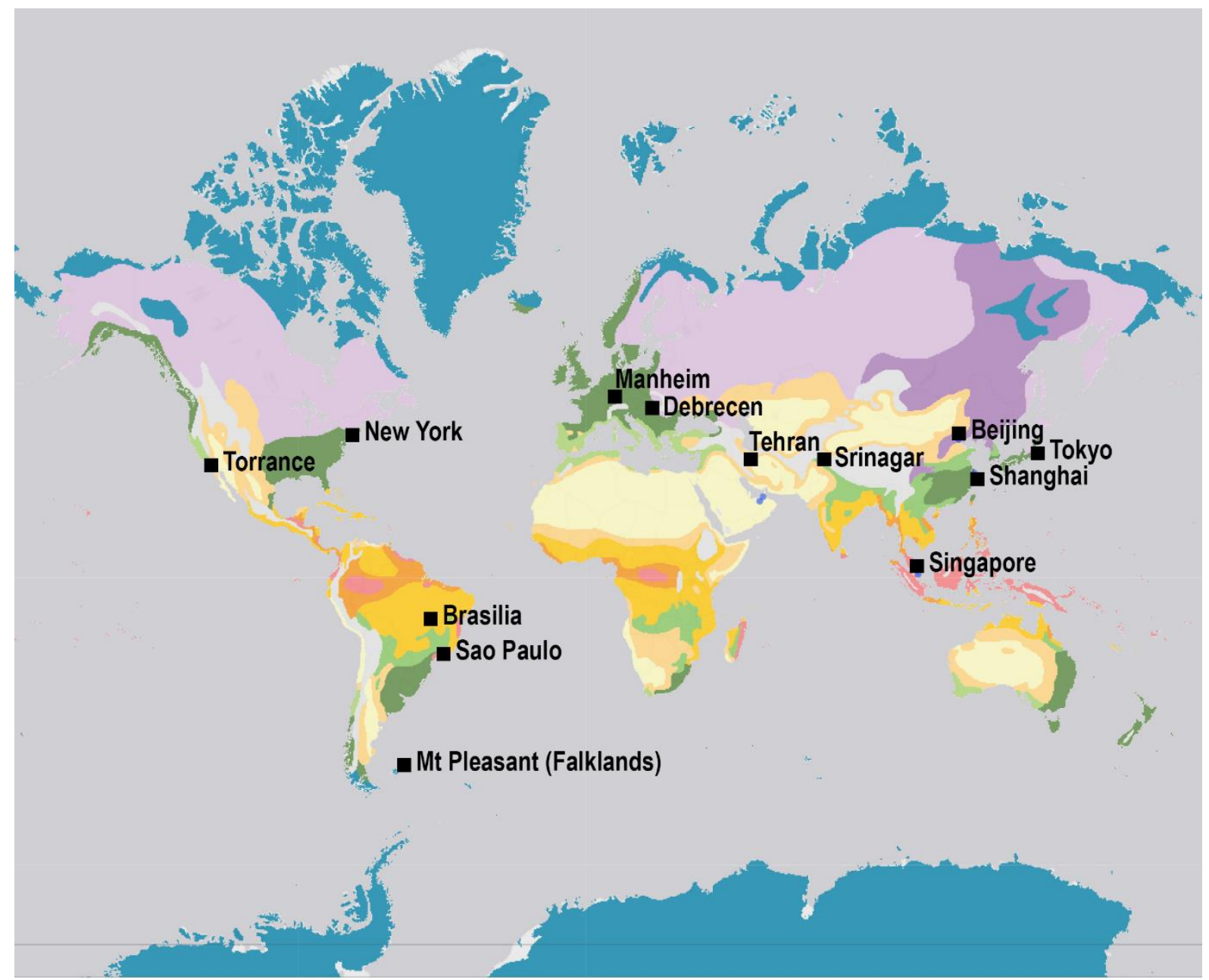

Humid Equatorial Climate - No Dry Season

Humid Equatorial Climate - Short Dry Season

Humid Equatorial Climate - Long Dry Season

Dry Climate - Semi Arid

Dry Climate - Arid

Humid Temperate Climate - No Dry Season

Dry Winter

Dry Summer

Humid Cold Climate - No Dry Season

Humid Cold Climate - Dry Winter

Cold Polar Climate - Tundra and Ice

Unclassified Highlands

Figure 2: Distribution of selected cities on world map

\subsection{Annual simulation setup}

In order to evaluate the performance of the WFG system for different climate over a year, a simulation model needs to be prepared. Building simulation tools such as TRNSYS in combination to LBL Window provide many possibilities for such a study, however due to the novelty of the WFG system, some special developments and configurations should be implemented in order to tail the simulation tools for this study. The first part (2.2.1.) described the optical and thermal behaviour of water in glazing system and how it is used in dynamic simulation. The geometry and construction properties of the building (2.2.2.), in addition to the mechanical systems and controls (2.2.3) implemented in annual simulations is explained later in this section.

\subsubsection{Simulating the optical and thermal behaviour of water in glazing system}

In terms of optical properties, regarding to the Beer Lambert law, the absorption and transmission of water layers can be calculated based on absorption coefficient $(\alpha[\mathrm{cm}-1])$ of pure water [28] [33] and the thickness of the water layer [cm]. Regarding the different solar and visible radiation transmission (and heat absorption) values, corresponding to the different thickness of water, water layer can be used 
as a smart selective layer. Previous studies showed the heat harvesting potential of different water layers [34] [35]. Based on the potential solar radiation on the earth's surface (ASTM E-490 AM0 Standard Spectra), a water layer with $1 \mathrm{~cm}$ thickness has $30 \%$ solar heat absorption (wavelength: $300-$ $2500 \mathrm{~nm}$ ), while allowing $99 \%$ of visible light (380-780 nm) to transmit. These values are $45 \%$ and $92 \%$ respectively for solar heat absorption and visible light transmission of $10 \mathrm{~cm}$ of water.

According to precedent studies [36], thermal properties of ordinary water such as molecular weight, conductivity, viscosity and specific heat coefficient are defined for different temperatures from zero to $50^{\circ} \mathrm{C}$.

Different configurations of the water filled glass system were set up in LBL Window 7.6 software for evaluating the thermal and optical behaviours. The optical properties of water layer (absorption and reflectivity) were defined first in Optics 6 and then exported to LBL Window to define a new shading material. The thermal conductivity of water is also defined based on different temperatures $\left(0-50^{\circ} \mathrm{C}\right)$ as a new gap gas in Window Gap library. Table 2 shows the steady state performance of the window systems with water layer under the CEN environmental conditions for the centre of the pane.

Table 2: U-value and optical properties of different window types base case and Water-filled glazing

\begin{tabular}{|l|l|l|l|l|l|}
\hline Type of Water Filled Glazing & $\begin{array}{l}\text { Case } \\
\text { Name }\end{array}$ & $\begin{array}{l}\text { U-value } \\
{[\mathbf{W} / \mathrm{m} 2-\mathrm{K}]}\end{array}$ & $\begin{array}{l}\text { SHGC } \\
{[\%]}\end{array}$ & $\begin{array}{l}\text { Tsol } \\
{[\%]}\end{array}$ & $\begin{array}{l}\text { Tvis } \\
{[\%]}\end{array}$ \\
\hline $\begin{array}{l}\text { Gap filled with argon, 16mm } \\
\text { (base case_no shade) }\end{array}$ & Base_0 & 1.4 & $62 \%$ & $43 \%$ & $62 \%$ \\
\hline $\begin{array}{l}\text { Gap filled with argon, 16mm } \\
\text { (base case_auto shaded, Fc=0.25) }\end{array}$ & Base_1 & 1.4 & $46 \%$ & $32 \%$ & $46 \%$ \\
\hline $\begin{array}{l}\text { Gap filled with air, 15mm } \\
\text { (base case) }\end{array}$ & WF_0 & 1.2 & $50 \%$ & $33 \%$ & $51 \%$ \\
\hline Gap filled with water, 15mm & WF_1 & 2.9 & $55 \%$ & $27 \%$ & $44 \%$ \\
\hline Gap filled with water, 100mm & WF_2 & 2.9 & $54 \%$ & $24 \%$ & $42 \%$ \\
\hline
\end{tabular}

For preparing the necessary data for an annual dynamic simulation, window properties for every window configuration should be imported as BSDF (Bidirectional Scattering Distribution Function) data sets (in addition to other thermal information of layers and gaps) from LBL Window into TRNSYS via trnBSDF tool [37]. BSDF data generated by LBL Window contains the solar and visible transmission and reflection in the format of Klems matrix (145X145). This method of modelling is one the most accurate models for a window with complex fenestration system in order to calculate radiative heat flux through a glazing system. This detailed window model in TRNSYS makes it possible to calculate the absorbed solar radiation and temperature for each layer and gap specifically.

The cooling effect of the water flow in optically transparent setting has been confirmed with field tests and monitoring of the Water House 2.0 pavilion in Taichung, Taiwan. The building was monitored for days with the pump turned on constantly and for additional days while being turned off. The results have shown that both surface and indoor temperature dropped significantly while the pump was operational. This effect was the result of the water flow as there was no other cooling system operational and ambient temperature and solar gain was similar for both cases.

Additionally, we verified these assumptions with measurements on absorption. We used a small prototype that can be filled with water as shown on Figure 3. A pyranometer model Klipp and Zonen SP Lite was used for the simulation. The thickness of the water layer in this prototype was the same as WF1 in the simulation $(10 \mathrm{~mm})$. The measurement was conducted outside for natural solar gain with horizontal and vertical setting. The glass was measured with and without water infill. The change in SHGC after water infill correlated with the $5 \%$ difference that was estimated in the simulation. We also confirmed the amount of changes in the visible spectrum with an LP Standard Pro spectrometer. The absorption showed no difference in the visible spectrum. 


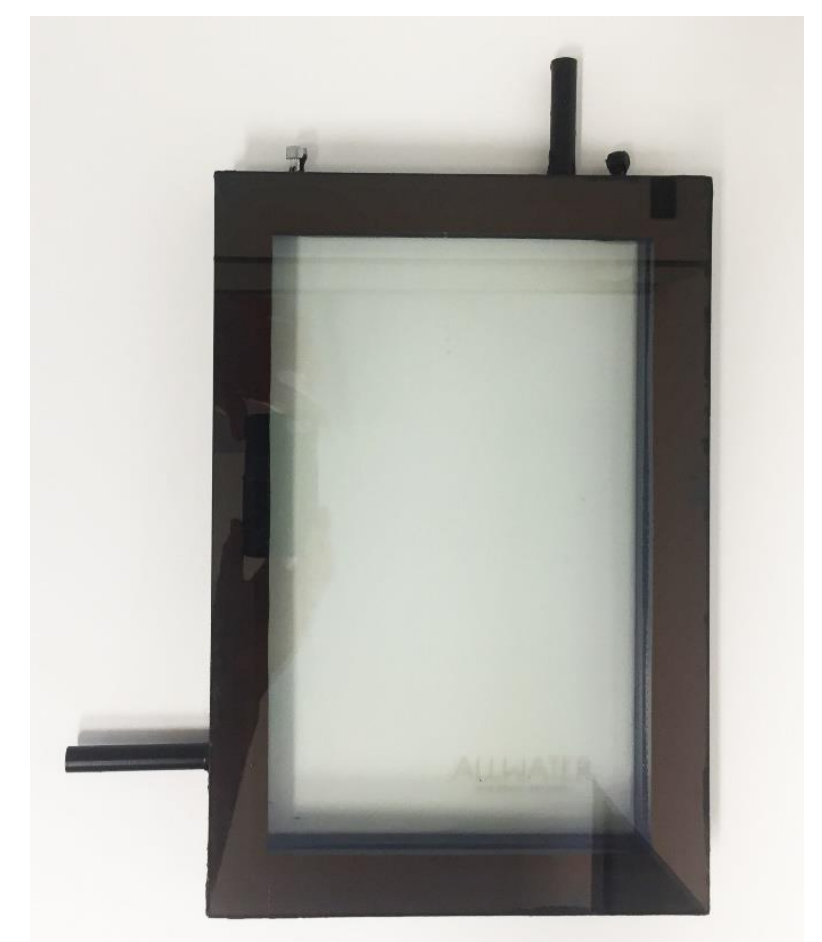

Figure 3: Water-filled Glass prototype used for measurements

The importance of this method (as mentioned above) is that the performance of WFG can be evaluated here as an integrated part of the whole building envelope and on a scale of a whole building (instead of focusing on a window). Another important aspect was that the simulation method introduced here is available (both Window and TRNSYS), compared to previous simulations that utilised bespoke coding.

\subsubsection{Reference room and standard glass types used for reference (description of the model)}

In this paper, the potential of water filled window is evaluated for a south oriented window (and north oriented for the cities located in southern hemisphere) for different climate conditions. To Evaluate the shading effect of the water layer it was reasonable to consider the orientation of a façade toward the equator with a big glazing area. The geometry of a standard office room is modelled for thermal simulation for one person $\left(17.50 \mathrm{~m}^{2}, 5.0 \mathrm{~m}\right.$ length, $3.5 \mathrm{~m}$ width and $3.0 \mathrm{~m}$ height) following the technical standard of VDI 2078:2012-03 (Figure 4). The window is $3.3 \mathrm{~m}$ by $2.8 \mathrm{~m}\left(9.24 \mathrm{~m}^{2}\right.$ area: WWR $\left.88 \%\right)$. In this model, the U-value of $0.19 \mathrm{~W} / \mathrm{m}^{2} \mathrm{~K}$ is assumed for the only external wall on the south façade and other walls, ceiling, and floor are assumed to be adiabatic.

For one occupant in an office space, corresponding internal gains $(130 \mathrm{~W} / \mathrm{m} 2$ for a person, and 140 $\mathrm{W} / \mathrm{m} 2$ for a computer) were applied in simulation during the working hours (Monday to Friday from 8:00 to $18: 00)$.

The Artificial lighting gain of $5 \mathrm{~W} / \mathrm{m}^{2}$ was added to the internal loads by controlling the 300 lux as minimum lux level with no dimming function.

The infiltration of the building assumed $n=0.25 \mathrm{ACH}$ which increases during the working hours into $\mathrm{n}=1.45 \mathrm{ACH}$. In addition, a night ventilation $(\mathrm{n}=5 \mathrm{ACH})$ was applied during summer time when T_room is greater than T_out. The infiltration values were set based on DIN 4108-2:2013 standard.

An ideal heating and cooling system were used with a cooling setpoint temperature of $25^{\circ} \mathrm{C}$ and a heating setpoint temperature of $21^{\circ} \mathrm{C}$ during the working hours. For the rest of the time building was controlled by applying some setbacks $\left(29^{\circ} \mathrm{C}\right.$ for cooling and $15^{\circ} \mathrm{C}$ for heating). 


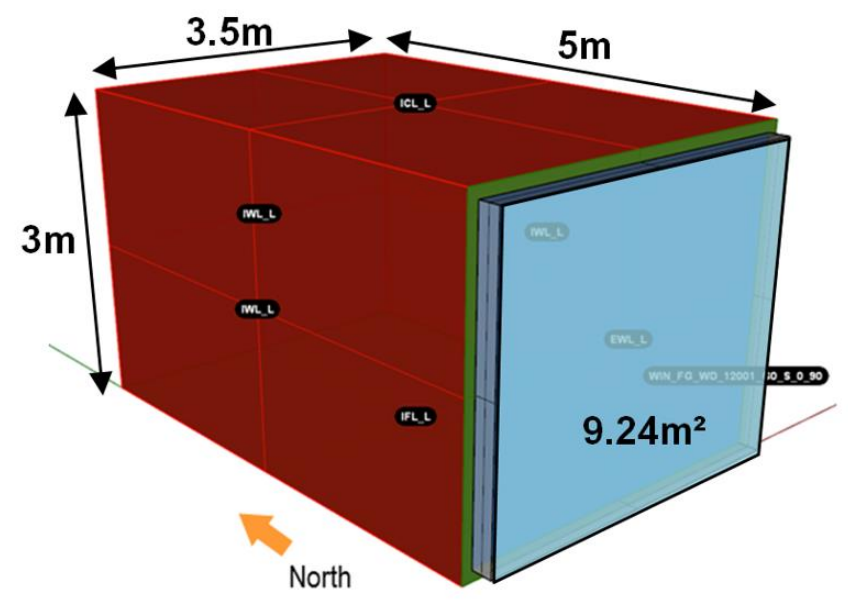

Figure 4: Reference room 3D model used for simulation

A conventional double glazing window with Low-E coating and U-value of $1.4 \mathrm{~W} / \mathrm{m}^{2} \mathrm{~K}$ and $0.62 \mathrm{SHGC}$ value is considered for the base cases. Base case zero (Base_0) is the unprotected clear window and base case one (Base_1) is by using an external movable shading system. The shading system with $75 \%$ shading fraction ( $\mathrm{FC}=0.25)$ was controlled during the simulation based on the total solar irradiation (IT) on the window surface (following DIN:4108-2 standard when IT>200 W/m² for south window). The window frame fraction is neglected for all cases in this study.

It is important to review the advantages of WFG here, which would clarify why WFG should be used in and why these reference options are the most ideal. Firstly, WFG was compared with clear glass options because one of its main advantages is optical transparency: as mentioned, water provides good heat absorption without impacting the visible spectrum, which is why we decided to use the same type of clear glass for both references and WFG. In case one uses coating (i.e. Low-E coating) with WFG, the performance would improve just like in case of standard glass. The intention here was to emphasize that WFG can perform very well even with clear glass layout. Secondly, another benefit of WFG is its energy performance compared to standard glass. We compared WFG with the option of utilizing moveable shading and good U-value (Base_1). Another option was to compare WFG with more advancing glazing, such as EC for instance, but this would have yielded an unfair comparison because WFG is optically transparent while EC is not and because WFG could be made darker, which would improve its energy performance further. A comparison of such type of WFG and EC would yield better results. Utilizing clear glass for every option would lead to potential visual discomfort (solar glare), which would require some kind of solar shading indoors (i.e. curtain), but such options are still more costeffective than external shadings or advanced glazing options.

In order to assess the energy saving performance of the proposed system, three different water filled glazing systems with different shading effects have been defined.

As Figure 5 shows, main construction make-up for proposed window system is a conventional triple glazing system with three glass panes and two cavities. The outer gap is $8 \mathrm{~mm}$ thick and filled with Argon. The inner gap is $15 \mathrm{~mm}$ thick and can be filled (or evacuated) with water. Configuration zero (WF_0) is filled with air in the inner gap. The configuration 1 (WF_1) is the same makeup, where the inner cavity is filled with pure water. Even though it might be not feasible to have a $10 \mathrm{~cm}$ water layer, the configuration 2 (WF_2) is also simulated to show the potential of the pure water layer in absorbing solar gain.

By comparing the amount of annual energy demand [kWh/m2.a] for heating, cooling and artificial light per square meter between water-filled configurations and the base cases the annual performance of the proposed system can be evaluated. Comparison between Base case zero (Base_0) and water filled glass (WF_1) evaluates two window systems with the same visual properties. Both provide an unobstructed view to the outside and daylight availability. While observing the water filled glass system configuration 0 and 2 (WF_0 and WF_2) can magnify the potential performance of water layer in a glazing system. Moreover, comparison between Base case 1 (Base_1) and water filled glass (WF_1) shows the performance of system in light of the existing industry standard (market viability and fairness). 


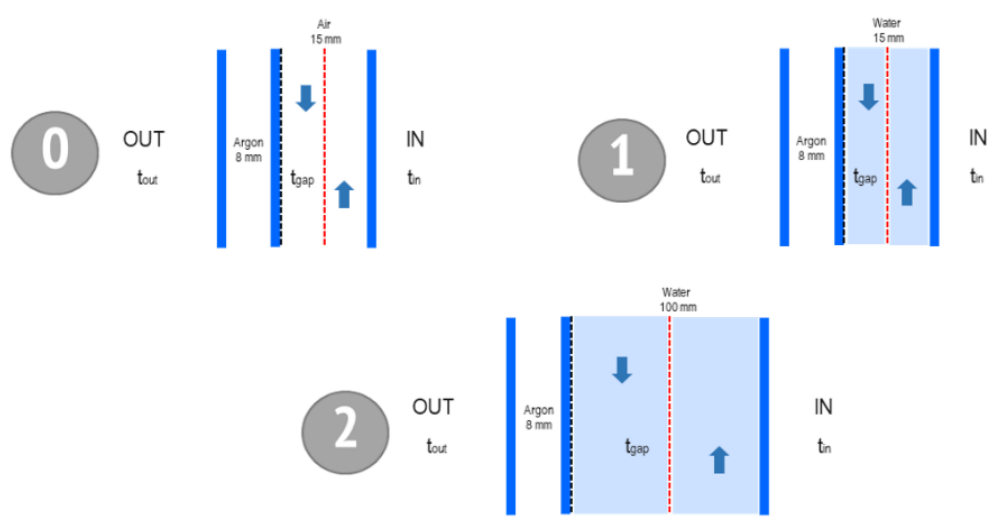

Figure 5: Layout of WFO, WF1 and WF2 windows. The simulation utilizes a virtual (dummy) layer (shown with red dashed line) that provides the absorption properties identical to the water layer with the given thickness.

\subsubsection{Options for mechanical systems and control}

Based on the possible mechanical systems such as "Constant water temperature" and "Heat storage" described in section 2.1.2. and the idea of "water as blood" [34], The annual simulations are defined for two scenarios for A) summer and B) winter period:

A) In summer, according to the solar absorption potential of water layer, by gaining solar radiation inside water flow, the system can effectively avoid the problem of overheating and consequently reduce cooling loads.

The excessive heat absorbed in the water layer (as sunshade) can be rejected to the earth underground micro-piles (or a heat exchanger to soil temperature) or radiated to the cold sky over night. Therefore, a control is applied in the simulation to keep water circulating during the summer period for cooling purpose. More than rejecting the heat to the underground, collected heat might be used for preheating the domestic hot water too. Annual ground temperature can be different because of climate. In this study, we used the Transys Type 77 model to calculate the ground temperatures for each day and location, which can be also found in the Soil Temperature Tables in the ASHRAE Handbooks [37].

B) In winter, for collecting heat, the mass flow rate needs to be regulated by the function of water temperature. During a winter day, the water should be kept in the cavity until it reaches the required temperature $\left(35^{\circ} \mathrm{C}\right)$. So, while the sufficient amount of visible light is transmitting to the space, collected heat on the water layer can be used to support heating the room (used for a low temperature radiant heating system or for providing domestic hot water).

During a cold night or a cloudy day in winter, evacuating the water cavity completely improves the U-value and plays the role of night insulation to reduce heat loss, however this option was not applied in this study.

The heat balance shows how much solar radiation is blocked, how much is entering through the glazing and how much is exchanged via longwave radiation or convection with surrounding surfaces and air-nodes during the dynamic behaviour of buildings. The absorption of radiation increases temperature in water layer. This leads to a heat flux both toward the room and outside (ambient). Considering the heat balance algorithm implemented in TRNSYS (Type 56), the net solar radiation absorbed in water layer $\left(\mathrm{Q}_{\text {abs-water }}\right)$ can be calculated, as well as the heat loss toward the room (Qloss-inward) including convective and radiative (long-wave) heat flow from water layer to the air and walls and surfaces of the room.

During wintertime (heating period), solar radiation harvested in the WFG can be used for heating in building. In addition, the heat loss toward the room is the positive impact of WFG which heats up the room directly.

Therefore, estimating the full potential of water layer as a solar collector, the net solar radiation absorbed in water layer $\left(\mathrm{Q}_{\text {abs }}\right)$ can be added to the heat loss toward the room ( $\left.\mathrm{Q}_{\text {loss-in }}\right)$ 
and be summed over the heating period (equation 1). In this study, annual $\mathrm{Q}_{\mathrm{useful}}[\mathrm{kWh} / \mathrm{a}]$ is defined as a representative parameter for solar harvesting potential of the WFG system. The bigger the $\mathrm{Q}_{\text {usefull, }}$ the better the performance of WFG during the heating period.

$$
\mathrm{Q}_{\text {usefull }}=\Sigma\left(\mathrm{Q}_{\text {abs-water }}+\mathrm{Q}_{\text {loss-inward }}\right) \quad \text { Eq. } 1
$$

Where:

Qabs-water

The solar radiation absorbed in water layer [W]

Qloss-inward

The energy flows from inner face of water cavity to the room [W]

\section{Results}

Following graph (Figure 6 and 7) demonstrates the annual performance of a south oriented office with $17.5 \mathrm{~m}^{2}$ floor area and a large window area $\left(9.24 \mathrm{~m}^{2}\right)$. The results include all five window configurations (Base_0\&1, and WF_0\&1\&2) for different climates (13 different cities). Annual energy demand $\left[\mathrm{kWh} / \mathrm{m}^{2} . \mathrm{a}\right]$ is split into the heating, cooling, and electricity demand for artificial lighting components as Q_Heat with red bars, Q_Cool with blue bars, and Q_Elec with yellow bars. The graph also shows the Q_useful $\left[\mathrm{kWh} / \mathrm{m}^{2}\right.$.a] as green bars which is the amount of useful solar heat gained during winter day in water flow for different water filled glass configurations (WF1\&2).

The full dataset of the simulation results has been uploaded to the data depository of Loughborough University and is available online. [39, 40, 41, 42, 43] 

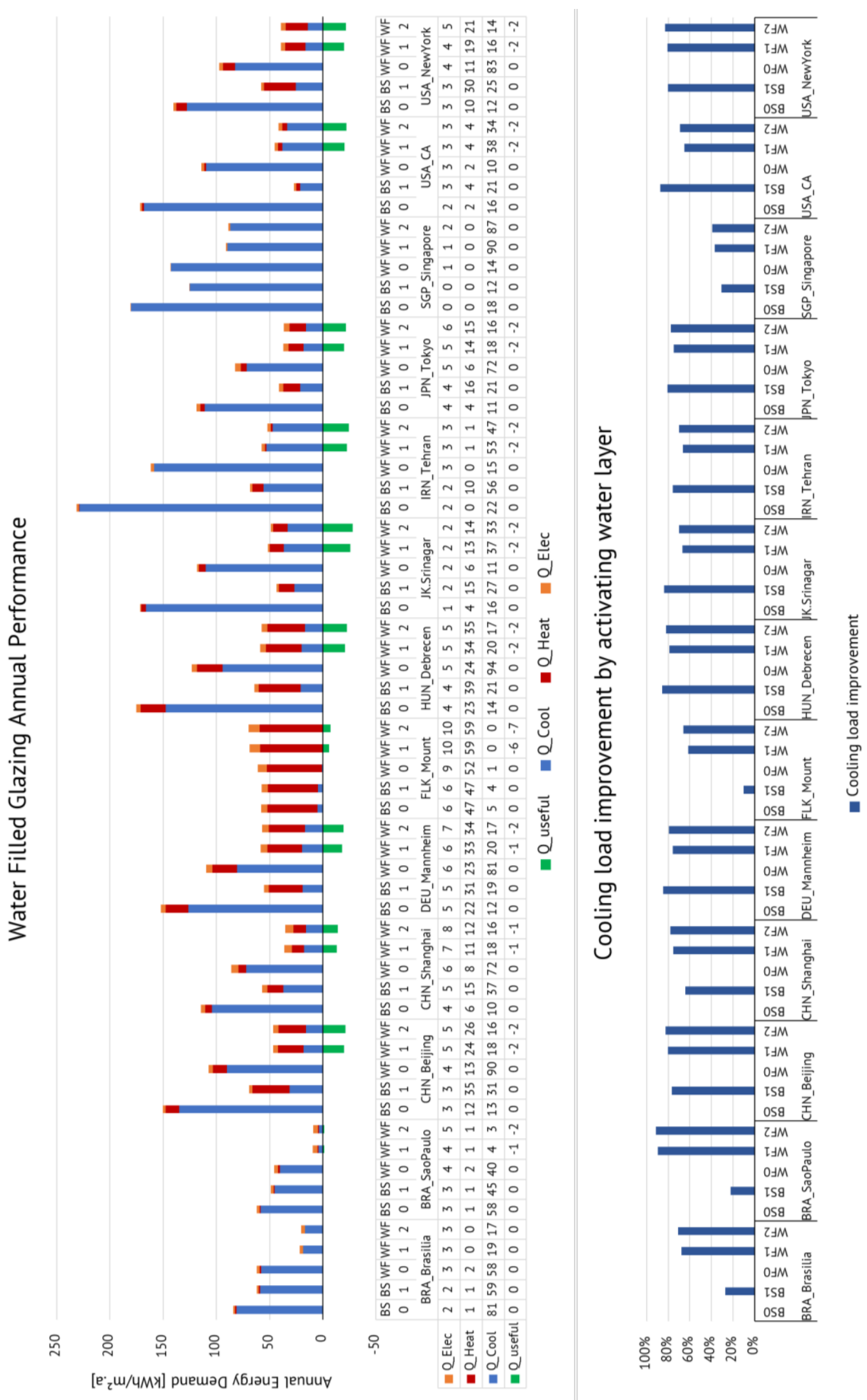

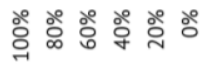

Figure 6: Annual energy performance of five window types in 13 cities. The types are: Double glass with argon and clear glass (Base0), DIN standard Double glass with argon, coating and automatic shading (Base 1), Water-filled glass without water and clear glass (WFO), Water-filled Glass with 15 $\mathrm{mm}$ water and clear glass (WF1) and Water-filled glass with $100 \mathrm{~mm}$ water and clear glass (WF2) 

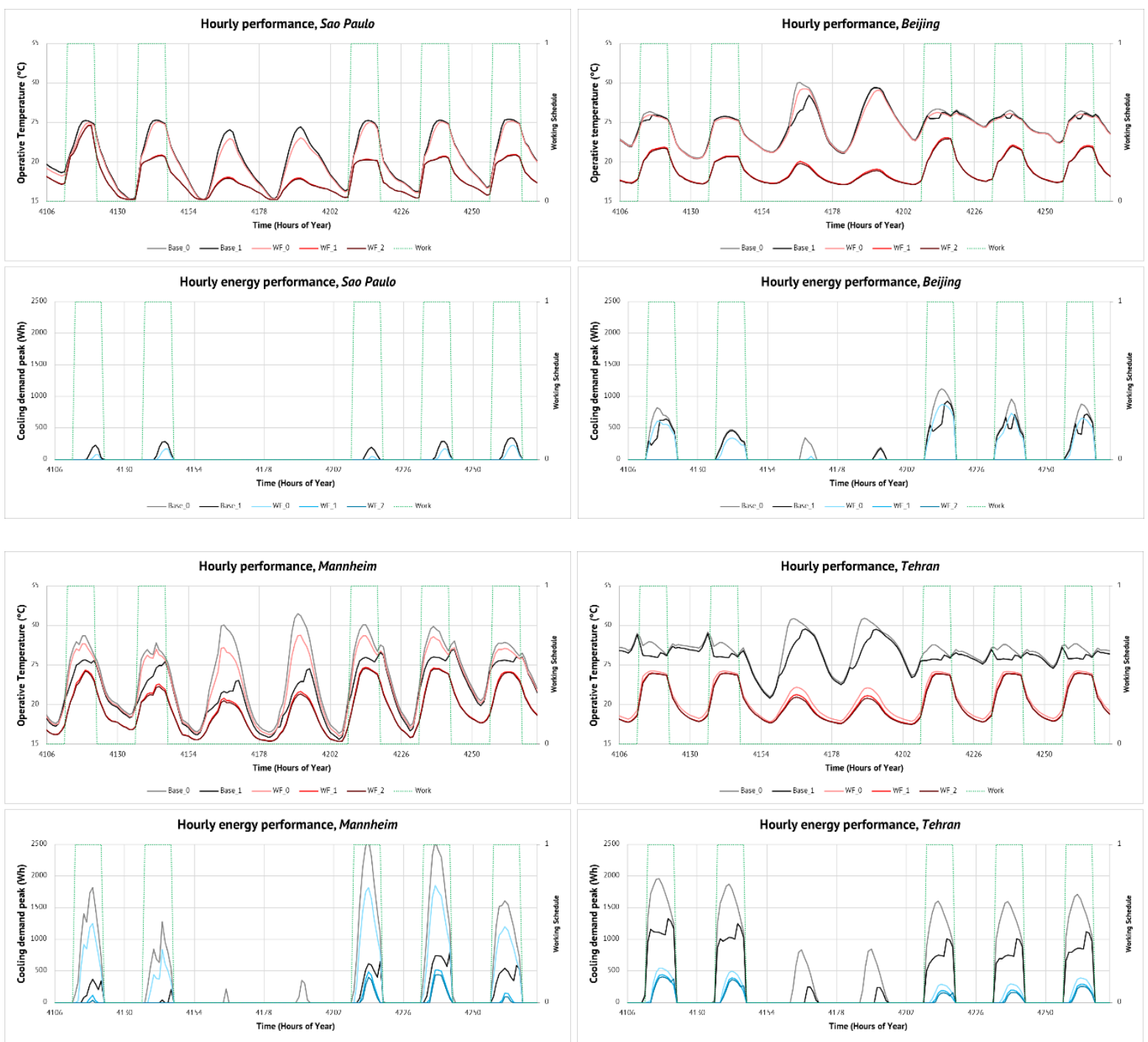

Figure 7: Hourly performance of five window types in a typical week (21st till $27^{\text {th }}$ of June) for four cities from different climate groups: Sao Paulo (absorption-based), Beijing (intermediate), Mannheim (hybrid), and Tehran (absorption-based).

The simulation evaluates the potential energy savings for each climate and classifies the 13 cases in the four identified climate groups by following four subsequent steps:

- First step was to divide the energy consumption according to demand for heating, cooling and lighting. If there is no significant heating demand (less than $20 \mathrm{kWh} / \mathrm{m} 2 . \mathrm{a}$ ), the climate is absorption-based.

- If there is a heating demand, the next step is to assess the overall energy balance (including increase in heating and savings in cooling). If the energy savings are overall positive, the climate belongs to intermediate climate group.

- If this is not the case but the absorbed heat can balance the losses, the climate belongs to the hybrid climate group.

- All other cases belong to insulation-based options.

The energy savings and climate groups are summarised in Table 3 and 4. All cases shown energy savings for WFG, except Mount Pleasant. Singapore, Brasilia, Sao Paulo and Tehran had minimal heating and significant cooling demand. These cities met the criteria for absorption-based climates. The energy savings were the highest for the first three cases: compared with Base1, the energy consumption dropped by $66 \%, 92 \%$ and $50 \%$ respectively. It should be noted that the energy performance of WFG varies between the same climate as well because the system performs better in climates where cooling load is resulted by solar load. The fourth city, Tehran is a good example, where the cooling load is high but the energy savings are only $16 \%$. 
Beijing, Shanghai, Debrecen (Hungary), Tokyo and New York were classified as intermediate climates. As expected, these cities show less energy savings (33\%, 37\%, $9 \%, 10 \%, 32 \%$ respectively) as a result of absorption of WFG because their energy demand is a combination of heating and cooling load. However, the performance is much better if the captured heat during heating period can be considered, which case the energy savings increase to $61 \%, 59 \%, 41 \%, 57 \%$ and $65 \%$ respectively, which also shows the significant impact of heating consumption compared to absorption-based cities, where the two type of operation shows no difference.

Mannheim, Srinagar (India) and Torrance (California) belong to the hybrid group: these cities have more significant heating demand and the absorption capacity alone was not sufficient to outperform the energy savings of a Base1 scenario. In these cases the reuse of the absorbed heat during heating periods was necessary to compete with insulated windows. The energy savings for such combined operation were viable: $24 \%, 39 \%$ and $9 \%$. Finally, the last city was Mount Pleasant, which has significant heating load and is located in polar climate. As it can be expected, WFG is not a strong competition for insulated windows in this area, simply because the low solar gain and high heating demand, which makes WFG ineffective. Combined absorption and heat reuse show better results but is still below the performance of an insulated glass. However, it should be noted that WFG is a clear glass without any coating in this simulation, which still provides two benefits. The first is WFG's aesthetic impact: compared to Base1, the glass is clear and offers better view, more natural illumination and no need for shading. The second is the potential for additional savings, which would be resulted by additional coatings added to WFG, which would eventually render it a viable technology even in polar climates.

Table 3: Energy savings of WFG in different climates

\begin{tabular}{|c|c|c|c|c|c|c|c|c|c|c|c|}
\hline \multirow[t]{2}{*}{ Cities } & \multicolumn{3}{|c|}{$\begin{array}{l}\text { Total energy demand } \\
\left(\mathrm{kWh} / \mathrm{m}^{2} . \mathrm{a}\right)\end{array}$} & \multirow{2}{*}{$\begin{array}{l}\text { Savings: } \\
\text { Base0- } \\
\text { WF1 }\end{array}$} & \multirow[t]{2}{*}{$\begin{array}{l}\text { Savings: } \\
\text { (\%) }\end{array}$} & \multirow{2}{*}{$\begin{array}{l}\text { Savings: } \\
\text { Base1- } \\
\text { WF1 }\end{array}$} & \multirow[t]{2}{*}{$\begin{array}{l}\text { Savings: } \\
\text { (\%) }\end{array}$} & \multirow{2}{*}{$\begin{array}{l}\text { Savings: } \\
\text { Base1- } \\
\text { WF1+Quseful }\end{array}$} & \multirow[t]{2}{*}{$\begin{array}{l}\text { Savings: } \\
\text { (\%) }\end{array}$} & \multirow[t]{2}{*}{$\begin{array}{l}\text { Climate } \\
\text { group }\end{array}$} & \multirow[t]{2}{*}{$\begin{array}{l}\text { Climate } \\
\text { Priority }\end{array}$} \\
\hline & $\begin{array}{l}\text { Base } \\
0\end{array}$ & $\begin{array}{l}\text { Base } \\
1\end{array}$ & $\begin{array}{l}\text { WF } \\
1\end{array}$ & & & & & & & & \\
\hline Brasilia & 84.1 & 62.1 & 21.7 & 62.4 & $74 \%$ & 40.4 & $65 \%$ & 40.4 & $65 \%$ & $\begin{array}{l}\text { absorption- } \\
\text { based }\end{array}$ & SHGC \\
\hline Sao Paulo & 61.8 & 49.1 & 9.3 & 52.5 & $85 \%$ & 39.8 & $81 \%$ & 41.1 & $84 \%$ & $\begin{array}{l}\text { absorption- } \\
\text { based }\end{array}$ & SHGC \\
\hline Beijing & 150.2 & 69.2 & 46.5 & 103.7 & $69 \%$ & 22.7 & $33 \%$ & 42.4 & $61 \%$ & intermediate & SHGC \\
\hline Shanghai & 114.7 & 57.1 & 36.2 & 78.5 & $68 \%$ & 20.9 & $37 \%$ & 33.8 & $59 \%$ & intermediate & SHGC \\
\hline Mannheim & 152.2 & 55.0 & 58.6 & 93.7 & $62 \%$ & -3.6 & $-6 \%$ & 14.3 & $26 \%$ & hybrid & Both \\
\hline Mt. Pleasant & 58.1 & 57.6 & 68.7 & -10.7 & $-18 \%$ & -11.1 & $-19 \%$ & -5.3 & $-9 \%$ & $\begin{array}{l}\text { insulation- } \\
\text { based }\end{array}$ & U-value \\
\hline Debrecen & 175.0 & 64.4 & 58.7 & 116.3 & $66 \%$ & 5.7 & $9 \%$ & 26.6 & $41 \%$ & intermediate & SHGC \\
\hline Srinagar & 171.5 & 43.3 & 51.8 & 119.7 & $70 \%$ & -8.5 & $-20 \%$ & 17.1 & $40 \%$ & hybrid & Both \\
\hline Tehran & 231.2 & 68.3 & 57.4 & 173.8 & $75 \%$ & 10.9 & $16 \%$ & 33.6 & $49 \%$ & intermediate & SHGC \\
\hline Tokyo & 118.6 & 41.0 & 37.3 & 81.3 & $69 \%$ & 3.7 & $9 \%$ & 23.7 & $58 \%$ & intermediate & SHGC \\
\hline Singapore & 180.7 & 125.3 & 91.0 & 89.7 & $50 \%$ & 34.3 & $27 \%$ & 34.3 & $27 \%$ & $\begin{array}{l}\text { absorption- } \\
\text { based }\end{array}$ & SHGC \\
\hline $\begin{array}{l}\text { Torrance, } \\
\text { CA }\end{array}$ & 171.6 & 27.2 & 45.2 & 126.4 & $74 \%$ & -18.0 & $-66 \%$ & 2.6 & $9 \%$ & hybrid & Both \\
\hline New York & 140.1 & 58.1 & 39.6 & 100.5 & $72 \%$ & 18.5 & $32 \%$ & 38.2 & $66 \%$ & intermediate & SHGC \\
\hline
\end{tabular}

Table 4 shows the economic value of energy savings for each city. (ROI was not calculated as the market price of WFG is not known yet). The following COPs were included in the model:

- $\quad \mathrm{COP}=1.0$ electricity consumption

- $\quad \mathrm{COP}=4.2$ heat pump (for heating)

- $\quad \mathrm{COP}=4.0$ chiller (for cooling)

The energy savings are shown in Figure 08 for each city. 
Table 4: Economic value of energy savings of WFG in different climates (US\$/m2.a)

\begin{tabular}{|c|c|c|c|c|c|c|c|c|c|c|c|c|c|c|}
\hline & & $\mathrm{COP}$ & & 1.0 & 4.2 & 4.0 & $\begin{array}{l}\text { Total Annual } \\
\text { Energy } \\
\text { Intensity } \\
\end{array}$ & EndE & ergy $[\mathrm{kWh}$ & m2.a] & PrimaryEnergy & Co2 Emission & $\begin{array}{l}\text { Electricity } \\
\text { cost }\end{array}$ & $\begin{array}{l}\text { Elec. cost } \\
\text { factor }\end{array}$ \\
\hline & & CaseName & $\begin{array}{l}\text { Q_useful } \\
{\left[\mathrm{kWh} / \mathrm{m}^{2} \cdot \mathrm{a}\right]}\end{array}$ & $\begin{array}{c}\text { Q_Elec } \\
{\left[\mathrm{kWh} / \mathrm{m}^{2} . \mathrm{a}\right]}\end{array}$ & $\begin{array}{l}\text { Q_Heat } \\
{\left[\mathrm{kWh} / \mathrm{m}^{2} . \mathrm{a}\right]}\end{array}$ & $\begin{array}{l}\text { Q_Cool } \\
{\left[\mathrm{kWh} / \mathrm{m}^{2} \cdot \mathrm{a}\right]}\end{array}$ & {$\left[\mathrm{kWh} / \mathrm{m}^{2} . \mathrm{a}\right]$} & Q_Elec & Q_Heat & Q_Cool & {$\left[\mathrm{kWh} / \mathrm{m}^{2} . \mathrm{a}\right]$} & {$\left[\mathrm{KgCO} 2 \mathrm{e} / \mathrm{m}^{2} . \mathrm{a}\right]$} & {$\left[\mathrm{US} \$ / \mathrm{m}^{2} \cdot \mathrm{a}\right]$} & [US\$/kWh] \\
\hline \multirow[b]{5}{*}{ BRA_Brasilia } & BS0 & Base case: always clear & 0 & 1.9 & 1.1 & 81.1 & 84.1 & 1.9 & 0.3 & 20.3 & 74.3 & 34.9 & 9.7 & 0.13 \\
\hline & BS1 & Base case: controled shading & 0 & 2.0 & 1.1 & 59.0 & 62.1 & 2.0 & 0.3 & 14.7 & 56.4 & 26.4 & 7.3 & \\
\hline & WF0 & WFG $0: 15 \mathrm{~mm}$ air filled & 0 & 2.7 & 1.5 & 57.7 & 61.9 & 2.7 & 0.4 & 14.4 & 57.8 & 27.1 & 7.5 & \\
\hline & WF1 & WFG $1: 15 \mathrm{~mm}$ water filled & 0 & 3.1 & 0.0 & 18.6 & 21.7 & 3.1 & 0.0 & 4.7 & 25.6 & 12.0 & 3.3 & \\
\hline & WF2 & WFG $2: 100 \mathrm{~mm}$ water filled & 0 & 3.4 & 0.0 & 16.9 & 20.3 & 3.4 & 0.0 & 4.2 & 25.4 & 11.9 & 3.3 & \\
\hline \multirow[b]{5}{*}{ BRA_SaoPaulo } & BS0 & Base case: always clear & 0 & 2.7 & 0.9 & 58.2 & 61.8 & 2.7 & 0.2 & 14.5 & 57.9 & 27.2 & 7.5 & 0.13 \\
\hline & BS1 & Base case: controled shading & 0 & 3.0 & 0.9 & 45.1 & 49.1 & 3.0 & 0.2 & 11.3 & 48.1 & 22.6 & 6.3 & \\
\hline & WF0 & WFG $0: 15 \mathrm{~mm}$ air filled & 0 & 3.8 & 1.6 & 40.4 & 45.8 & 3.8 & 0.4 & 10.1 & 47.3 & 22.2 & 6.1 & \\
\hline & WF1 & WFG $1: 15 \mathrm{~mm}$ water filled & -1 & 4.3 & 0.8 & 4.2 & 9.3 & 4.3 & 0.2 & 1.0 & 18.3 & 8.6 & 2.4 & \\
\hline & WF2 & WFG $2: 100 \mathrm{~mm}$ water filled & -2 & 4.7 & 0.9 & 3.5 & 9.1 & 4.7 & 0.2 & 0.9 & 19.2 & 9.0 & 2.5 & \\
\hline \multirow[b]{5}{*}{ CHN_Beijing } & BS0 & Base case: always clear & 0 & 2.8 & 12.5 & 134.9 & 150.2 & 2.8 & 3.0 & 33.7 & 130.8 & 61.4 & 10.5 & 0.08 \\
\hline & BS1 & Base case: controled shading & 0 & 3.2 & 34.6 & 31.3 & 69.1 & 3.2 & 8.2 & 7.8 & 63.8 & 29.9 & 5.1 & \\
\hline & WF0 & WFG $0: 15 \mathrm{~mm}$ air filled & 0 & 4.0 & 12.8 & 90.3 & 107.1 & 4.0 & 3.1 & 22.6 & 98.0 & 46.0 & 7.8 & \\
\hline & WF1 & WFG $1: 15 \mathrm{~mm}$ water filled & -20 & 4.6 & 24.1 & 17.9 & 46.5 & 4.6 & 5.7 & 4.5 & 48.8 & 22.9 & 3.9 & \\
\hline & WF2 & WFG $2: 100 \mathrm{~mm}$ water filled & -22 & 4.9 & 26.0 & 15.7 & 46.6 & 4.9 & 6.2 & 3.9 & 49.7 & 23.3 & 4.0 & \\
\hline \multirow[b]{5}{*}{ CHN_Shanghai } & BS0 & Base case: always clear & 0 & 4.5 & 6.2 & 104.0 & 114.7 & 4.5 & 1.5 & 26.0 & 105.8 & 49.6 & 8.5 & 0.08 \\
\hline & BS1 & Base case: controled shading & 0 & 4.9 & 15.1 & 37.1 & 57.1 & 4.9 & 3.6 & 9.3 & 58.8 & 27.6 & 4.7 & \\
\hline & WF0 & WFG $0: 15 \mathrm{~mm}$ air filled & 0 & 6.5 & 7.6 & 71.8 & 85.8 & 6.5 & 1.8 & 17.9 & 86.7 & 40.7 & 6.9 & \\
\hline & WF1 & WFG $1: 15 \mathrm{~mm}$ water filled & -13 & 7.3 & 11.1 & 17.8 & 36.2 & 7.3 & 2.6 & 4.5 & 47.8 & 22.4 & 3.8 & \\
\hline & WF2 & WFG $2: 100 \mathrm{~mm}$ water filled & -14 & 8.0 & 11.5 & 15.9 & 35.4 & 8.0 & 2.7 & 4.0 & 48.7 & 22.9 & 3.9 & \\
\hline \multirow[b]{2}{*}{ DEU_Mannheim } & BS0 & Base case: always clear & 0 & 4.5 & 21.6 & 126.1 & 152.2 & 4.5 & 5.1 & 31.5 & 136.3 & 63.9 & 45.0 & 0.33 \\
\hline & BS1 & Base case: controled shading & 0 & 4.5 & 31.3 & 19.2 & 55.0 & 4.5 & 7.5 & 4.8 & 55.4 & 26.0 & 18.3 & \\
\hline
\end{tabular}




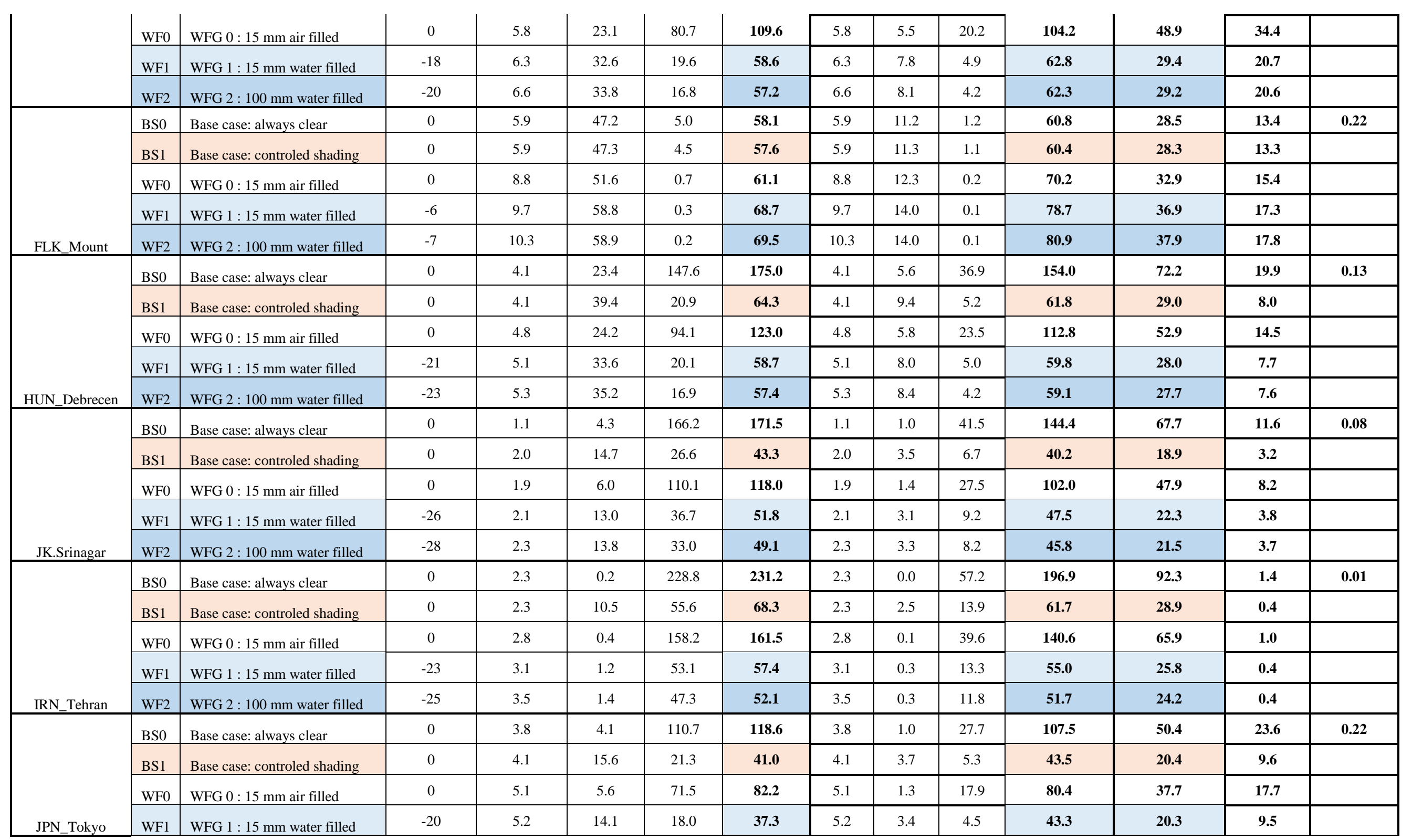




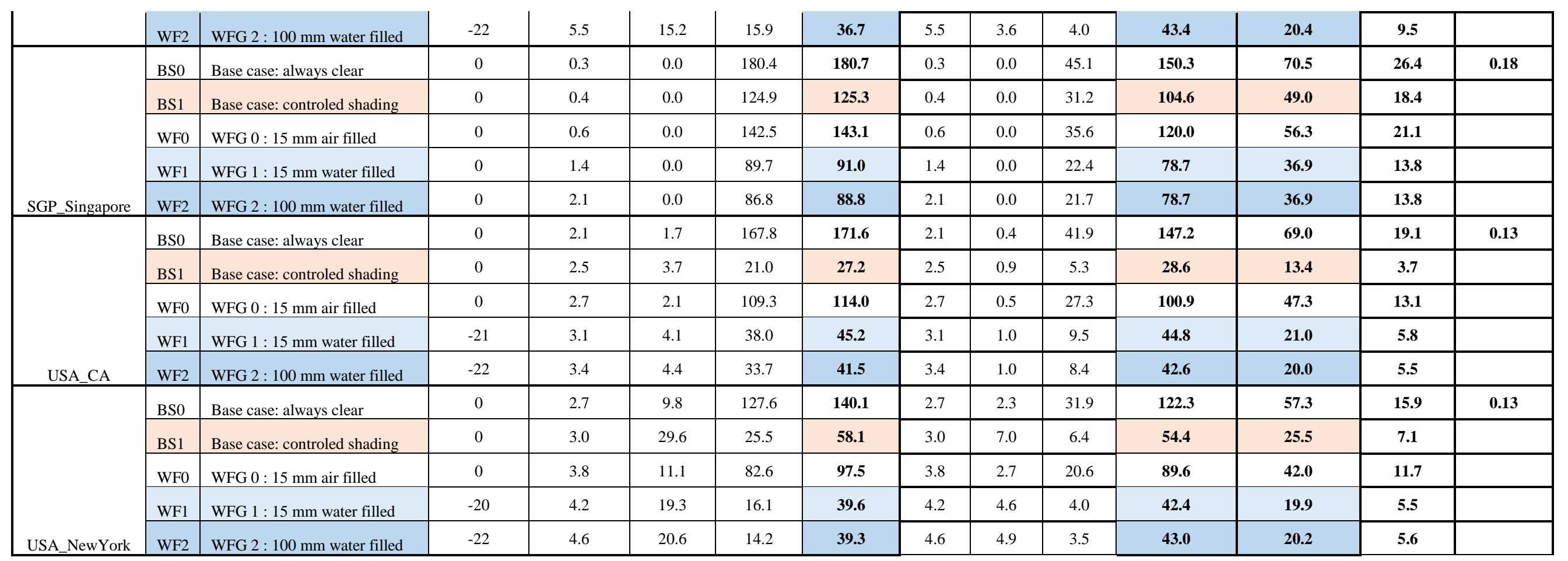




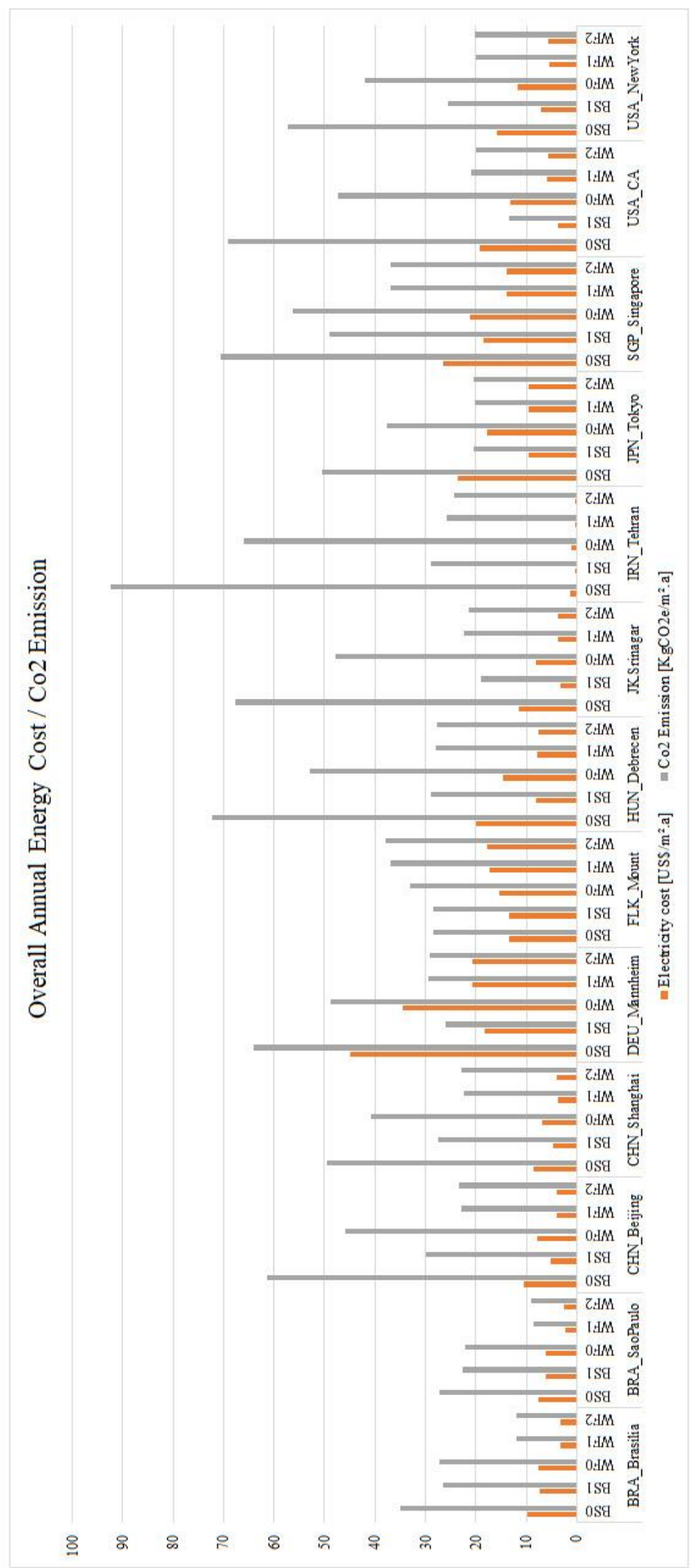

Figure 8: Overall energy consumption and CO2 emission in 13 cities and 5 cases (base0, base1, WFO, WF1 and WF2) 


\section{Discussion and Conclusions}

Water-flow glazing increases absorption capacity of a glass envelope at the cost of compromising insulation capacity ( $U$-value). This change is more advantageous in some climates than in others. The paper presents a global analysis of WFG thermal performance in 13 cities for the first time to evaluate the viability of the technology considering operation and energy savings based on absorption with or without reuse of the captured heat. Based on the WFG's impact on energy performance, operation and viability, four climate types can be determined: absorption-based, intermediate, hybrid and insulationbased climates. The difference between these climate groups is the way WFG operates and energy savings are achieved: only absorption, absorption with optional heat reuse or absorption with necessary heat reuse respectively. This shows the importance of the four climate groups introduced in this paper: since energy performance of WFG not only depends on ambient temperature and humidity but also on the annual distribution of solar gain (i.e. the proportion of solar gain during heating period) and the ground temperature. The paper shows that the four climate groups and the Köppen-Geiger classification does not overlap as the initial definitions would suggest.

The results of the energy simulation presented here have shown that in terms of glass facades SHGC has more impact on energy consumption in certain climates than insulation while others correlate more with changes in U-value. The simulation has shown that this applies to certain climates even if the absorption is improved at the cost of lower insulation capacity, which is the typical case for water-flow glass. Additionally, the simulation has shown that reusing the absorbed energy during heating period can make water-filled glass viable even in cold climates.

The results show that SHGC should be prioritised in absorption-based and intermediate climates and $\mathrm{U}$-value is more significant in insulation-based climates. Both values are Hybrid climate group, which means that a minimum level of insulation capacity is necessary to make the performance viable, but additional absorption capacity can improve the performance further.

Due to the climate specification we can determine different glass configuration, which suggests a nonuniform construction method for glass surfaces in different climates. This applies to WFG and also to other glass facades.

Water can be considered as an 'ideal coating' for glass envelopes, because its absorption capacity that absorbs heat without affecting visible spectrum. This enables WFG to utilise clear glass instead of tinted or coated alternatives.

The simulations compared WFG with a standard glass option combined with automated shading to evaluate WFG's potential of replacing shadings on glass facades. The results have shown that WFG is a good alternative for solid shading which offers better quality for lighting in spaces, especially in natural light and visual comfort.

Depending on the climate scenario, the energy savings can be between $9-84 \%$ compared to the identified Base case of a standard insulated double glass with automatic shading (DIN:4108-2 standard glass)

Considerations for future research:

Water-filled glass construction has some important challenges. The most important are the issues with water pressure, sealing, heat bridges and quality of water. These issues are not scope of this paper but were addressed and discussed in detail in another publication written by the author. Additionally, the layout of WFG presented here does not address the issues of potential glare effect and visual comfort as the result of utilising clear glass and increased solar gain. Because the absorption performance of the water, this has a much less impact on thermal comfort, but the issues of visual impact remains. This can be ideally resolved with internal shading or by changing the opacity of the water to filter the light. The latter has impact on the overall thermal performance of the water, which should be investigated further in future publications. Finally, the system has the potential to be used for building refurbishments, which the authors intend to explore in another publication in the future.

The energy performance of WFG has been considered as integrated in a building. This simulation approach enables us to evaluate the impact of WFG energy performance as a retrofit window, which will be subject of future research. Additionally, the water in WFG could be changed to have an integrated shading effect, which could be compared to switchable glazing on a global scale. 


\section{References}

[1] DeForest, N., Shehabi, A., Selkowitz, S., Milliron D.J., A comparative energy analysis of three electrochromic glazing technologies in commercial and residential buildings, Applied Energy 192 (2017) 95-109

[2] Ghosh, A., Norton, B., Duffy, A., Measured thermal performance of a combined suspended particle switchable device evacuated glazing, Applied Energy 169 (2016) 469-480

[3] Hemaida, A., Ghosh, A., Sundaram, S., Mallick, T.K., Evaluation of thermal performance for a smart switchable adaptive polymer dispersed liquid crystal (PDLC) glazing, Solar Energy 195 (2020) 185-193

[4] M. Arici, H. Karabay, M. Kan, Flow and heat transfer in double, triple and quadruple pane windows, Energy and Build. 86 (2015) 394-402.

[5] K.A.R. Ismail, C.T. Salinas, J.R. Henriquez, A comparative study of naturally ventilated and gas filled windows for hot climates, Energy Conservation and Management 50 (2009) 1691-1703.

[6] J.S. Carlos, Optimizing the ventilated double window for solar collection, Solar Energy 150 (2017) 454-462.

[7] T.T. Chow, C. Li, Z. Lin, Innovative solar windows for cooling-demand climate, Solar Energy Materials \& Solar Cells 94 (2010) 212-220.

[8] M. Gutai, Gyermek művészeti múzeum és műhely, Kecskemét, Epiteszforum. (2008). http://epiteszforum.hu/gyermek-muveszeti-muzeum-es-muhely-kecskemet (accessed September 2, 2019).

[9] M. Gutai, 2009, Dissolution Method and Water House Model, PhD thesis, University of Tokyo, Tokyo

[10] Matyas Gutai, inventor, Heat energy system for heating or maintaining thermal balance in the interior of building or building parts Japan patent 6250530. March 23, 2012.

[11] P.G. Loutzenhiser, H. Manz, S. Moosberger, G.M. Maxwell, An empirical validation of window solar gain models and the associated interactions, Int. J. Therm. Sci. 48 (2009) 85-95.

[12] K.A.R. Ismail, J.R. Henríquez, Two-dimensional model for the double glass naturally ventilated window, Int. J. Heat Mass Transf. 48 (2005) 461-475.

[13] P. Sierra, J. A. Hernandez, Solar heat gain coefficient of water flow glazings, Energy and Buildings 139 (2017) 133-145.

[14] A. Gasparella, G. Pernigotto, F. Cappelletti, P. Romagnoni, P. Baggio, Analysis and modelling of window and glazing systems energy performance for a well-insulated residential building, Energy Build. 43 (2011) 1030-1037.

[15] V.P. Bui, H.Z. Liu, Y.Y. Low, T. Tang, Q. Zhu, K.W. Shah, E. Shidoji, Y.M. Lim,W.S. Koh, Evaluation of building glass performance metrics for the tropical climate, Energy and Build. 157 (2017) 195-203

[16] T. T. Chow, C. Li, Z. Lin, The function of solar absorbing window as water-heating device, Building and Environment 46 (2011) 955-960.

[17] T. Gil-Lopez, C. Gimenez-Molina, Influence of double glazing with a circulating water chamber on the thermal energy savings in buildings, Energy and Buildings 56 (2013) 56-65.

[18] C. Li, T. T. Chow, Water-filled double reflective window and its year-round performance, Proc. Environmental Science 11 (2011) 1039-1047.

[19] T. T. Chow, C. Li, Z. Lin, thermal characteristics of water-flow double-pane window, International Journal of Thermal Science 50 (2011) 140-148.

[20] Y. L. Lyu, T. T. Chow, Evaluation of influence of header design on water flow characteristics in window cavity with CFD, Energy Proceedings 78 (2015) 97-102.

[21] T.T. Chow, Y. Lyu, Effect of design configurations on water flow window performance, Solar Energy 155 (2017) 354-362.

[22] T. T. Chow, Y. Lyu, Numerical analysis on the advantage of using PCM heat exchanger in liquidflow window, Applied Thermal Engineering 125 (2017) 1218-1227. 
[23] Y.L. Liu, T.T. Chow, J.L. Wang, Numerical prediction of thermal performance of liquid-flow window in different climates with anti-freeze, Energy 157 (2018) 412-423.

[24] P. Parke, Meet the man who builds houses with water - CNN, CNN. (2016). https://edition.cnn.com/2015/04/08/tech/water-house-matyas-gutai/index.html (accessed September 2, 2019).

[25] Experimental - Future Projects - 2017 | World Architecture Festival, (2017). https://www.worldarchitecturefestival.com/experimental-future-projects-2017 (accessed September 2, 2019).

[26] M. Gutai, Trans-structures, Actar Publishing, New York, 2015.

[27] Kottek, M., Grieser, J., Beck, C., Rudolf, B., Rubel, F., World map of the Köppen-Geiger climate classification updated, Meteorologische Zeitschrift 15, Issue 3 (2006) 259-263

[28] Pope, Robin M., and Edward S. Fry. "Absorption spectrum (380-700 nm) of pure water. II. Integrating cavity measurements." Applied optics 36, no. 33 (1997): 8710-8723.

[29] Yong, T.L., Djamila, H., Exploring köppen-geiger climate classification of the ashrae RP-884 database, International Journal of Recent Technology and Engineering 7, Issue 6 (2019) 854-860

[30] Bimaganbetova, M., Memon, S.A.Email Author, Sheriyev, A., Performance evaluation of phase change materials suitable for cities representing the whole tropical savanna climate region, $\underline{\text { Renewable }}$ Energy (2019), article in press

[31] Raziei, T., Köppen-Geiger climate classification of Iran and investigation of its changes during 20th century, Journal of the Earth and Space Physics 43, Issue 2 (2017) 419-439

[32] Binarti, F., Koerniawan, M.D., Triyadi, S., Utami, S.S., Matzarakis, A., A review of outdoor thermal comfort indices and neutral ranges for hot-humid regions, Urban Climate 31 (2020) Article number 100531

[33] Palmer, Kent F., and Dudley Williams. "Optical properties of water in the near infrared." JOSA 64, no. 8 (1974): 1107-1110.

[34]A. Ganji Kheybari, J. Lam, Adaptive Building Envelope: Performative Water-filled ETFE Cushions, Los Angeles, Façade Tectonics World Congress, (2016) pages: 27-38.

[35] A. Ganji Kheybari, J. Lam, Building Envelope as Heat Generator: The impact of Water-filled ETFE Cushion on Energy saving and Comfort, Powerskin conference proceedings, TU Munich, Germany (2017) pages: 27-38.

[36] Wagner, Wolfgang, and Andreas Pruß. "The IAPWS formulation 1995 for the thermodynamic properties of ordinary water substance for general and scientific use." Journal of Physical and Chemical Reference Data 31, no. 2 (2002): 387-535.

[37] Trnsys 18 - Type 56: Complex Fenestration Systems Tutorial, January 2017, M. Hiller, J. Merk, P. Schöttl

[38] Klein, S. A., Beckman, W. A., Mitchell, J. W., Duffie, J. A., Duffie, N., Freeman, T., Kummer, J. (2009). TRNSYS 17: A Transient System Simulation Program: Mathematical Reference. University of Wisconsin: Madison, WI, USA.

[39] Gutai, Matyas; Kheybari, Abolfazl Ganji (2020): WFG Overall Simulation. figshare. Dataset. https://doi.org/10.17028/rd.lboro.11625777

[40] Gutai, Matyas; Kheybari, Abolfazl Ganji (2020): WFG Beijing. figshare. Dataset. https://doi.org/10.17028/rd.lboro.11625792

[41] Gutai, Matyas; Kheybari, Abolfazl Ganji (2020): WFG Mannheim. figshare. Dataset. https://doi.org/10.17028/rd.lboro.11625804

[42] Gutai, Matyas; Kheybari, Abolfazl Ganji (2020): WFG Sao Paulo. figshare. Dataset. https://doi.org/10.17028/rd.lboro.11625807

[43] Gutai, Matyas; Kheybari, Abolfazl Ganji (2020): WFG Tehran. figshare. Dataset. https://doi.org/10.17028/rd.lboro.11625810 